\title{
Rearfoot strikers have smaller resultant tibial accelerations at foot contact than non-rearfoot strikers
}

\author{
Molly D Glauberman, Peter R Cavanagh* \\ From 4th Congress of the International Foot and Ankle Biomechanics (i-FAB) Community \\ Busan, Korea. 8-11 April 2014
}

\section{Purpose}

Overuse injuries are common in recreational runners. Recent reports have implicated the characteristics of the footstrike in the etiology of stress responses in the tibia. This has motivated efforts to modify the loading at footstrike by altering the orientation of the foot at first contact. The present study aimed to: 1 ) report typical magnitudes of resultant tibial acceleration (TA) in women distance runners; 2) contrast TA in rearfoot and non-rearfoot striking runners; and 3) examine TA during non-natural footstrike patterns in runners.

\section{Method}

We used a leg-mounted tri-axial acceleration monitoring unit to measure TA and angular velocities. Twenty injury-free women distance runners (age 27.8 \pm 3.7 years, height $168.1 \pm 6.2 \mathrm{~cm}$, body mass $59.2 \pm 7.3 \mathrm{~kg}$, weekly mileage $>20$ ) participated in the study. The sensor was positioned $5 \mathrm{~cm}$ above the medial malleolus along the medial tibial border and tensioned to $22 \mathrm{~N}$ with a Velcro strap. Multiple 60 -second running trials at $3.13 \mathrm{~m} / \mathrm{s}$ on a force-measuring treadmill (Kistler 9287 plate) were collected.

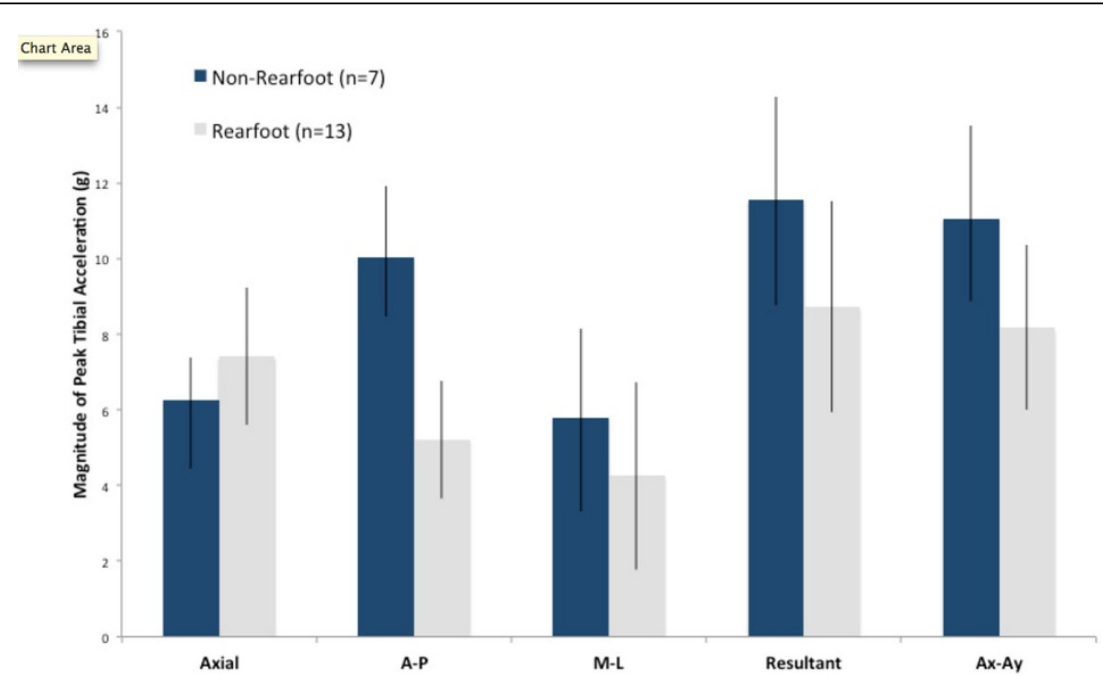

Figure 1 Peak tibial acceleration in rearfoot $(n=13)$ and non-rearfoot $(n=7)$ strikers in Brooks Adrenaline shoes.

* Correspondence: cavanagh@uw.edu

Deparment of Orthopaedics and Sports Medicine, University of Washington, Seattle, WA, 98195, USA 


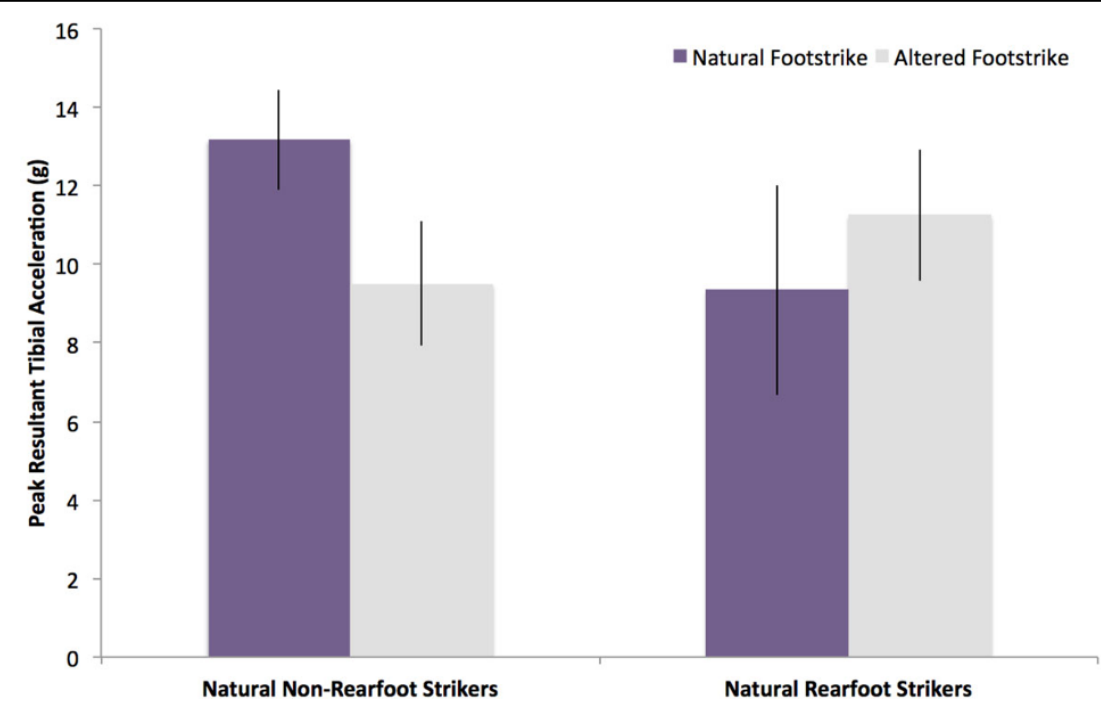

Figure 2 Peak resultant tibial acceleration in runners who ran with an altered footstrike $(n=18)$ while wearing their own shoes.

\section{Results}

The range of values for axial peak tibial acceleration (PTA) in the group was $4.6 \mathrm{~g}$ to $10.9 \mathrm{~g}$. Axial PTA in 7 non-rearfoot strikers $(6.3 \pm 1.1 \mathrm{~g})$ was not significantly different from that in rearfoot strikers $(7.4 \pm 0.8 \mathrm{~g} ; \mathrm{p}=0.15)$. However, the anterior-posterior acceleration component and the resultant PTA in non-rearfoot strikers (10.0 $\pm 1.9 \mathrm{~g}$ ) were significantly greater than that in rearfoot strikers (5.2 $\pm 1.6 \mathrm{~g} ; \mathrm{p}=<0.001)$ (Figure 1). In a second part of the study, twelve natural rearfoot runners were instructed to change their strike pattern to a non-rearfoot strike while 6 non-rearfoot strikers changed to a rearfoot pattern. The average resultant PTA for the natural rearfoot strikers increased from $9.4 \mathrm{~g}$ to $11.3 \mathrm{~g}$, whereas 6 natural non-rearfoot strikers decreased to $9.5 \mathrm{~g}$ from $13.2 \mathrm{~g}$ when switching to rearfoot striking (Figure 2).

\section{Conclusions}

It is not advantageous for rearfoot strikers to transition to non-rearfoot striking if PTA is the criterion measure. Previous studies that have only examined the axial component of tibial acceleration may have reached the wrong conclusion because the A-P component is the larger component in non-rearfoot strikers. Our findings suggest that a transition away from rearfoot striking is likely to increase tibial acceleration at footstrike. Thus, if tibial stress injuries are indeed related to resultant tibial acceleration at footstrike, a change to non-rearfoot striking may increase the risk of injury.

\section{doi:10.1186/1757-1146-7-S1-A93}

Cite this article as: Glauberman and Cavanagh: Rearfoot strikers have smaller resultant tibial accelerations at foot contact than non-rearfoot strikers. Journal of Foot and Ankle Research 2014 7(Suppl 1):A93.

\section{Submit your next manuscript to BioMed Central} and take full advantage of:

- Convenient online submission

- Thorough peer review

- No space constraints or color figure charges

- Immediate publication on acceptance

- Inclusion in PubMed, CAS, Scopus and Google Scholar

- Research which is freely available for redistribution

Submit your manuscript at www.biomedcentral.com/submit
C Biomed Central 